\title{
IMPLEMENTASI KEBIJAKAN EARMARKING TAX PAJAK BAHAN BAKAR KENDARAAN BERMOTOR DI KOTA BEKASI
}

\author{
Devi Purnama Sari, Taufik Silfian, Septian Khaerul Ghany ${ }^{1}$ \\ Email: septian.k.g@ gmail.com ${ }^{1}$ \\ Institut Ilmu Sosial dan Manajemen STIAMI
}

\section{ARTICLE INFO}

Keywords:

Implementation Policy, Earmarking Tax, Vehicle Fuel Tax

\begin{abstract}
The phenomenon of this study is about implementation Earmarking Tax of Pajak Bahan Bakar Kendaraan Bermotor - Vehicle Fuel Tax having allocation of fund is $70 \%$ for reduce of air pollution and environment damage. The purpose of this study is known and analyze of implementation policy earmarking tax vehicle fuels tax in Bekasi City and also entity of support and entity of inhibition on implementation this policy. Method of this study is using qualitative approach with descriptive specificity. The result of this study is implementation policy earmarking tax upon vehicle fuels tax in Bekasi City of West Java to the objective and target policy is as the allocation of funds to pressure the impact of of tax object with target policy is society by focuses to the negative impact of tax object. The activity of the policy on existing tax is in accordance with SOP, but implementation of the allocation fund is not in accordance with regulatations. The result of the activities of the policy of Earmarking Tax PBBKB not yet maximum utilization of allocation funds of activities budgeted. Enity of support has been the use of administrative systems and IT systems in the implementation of the policy of collecting Vehicle Fuel Tax such as Ring Code. While the entity inhibits the policy or rules and organizational structure. Because the Municipal Government of Bekasi has no special regulations governing the allocation of funds. And SKPD associated with the implementation of earmarking tax is still less active and less understanding of the policy.
\end{abstract}

\section{INTRODUCTION}

Indonesia telah menerapkan kebijakan otonomi daerah dimulai tahun 1999 dengan berdasarkan UndangUndang nomor 22 tahun 1999. Otonomi daerah merupakan sebuah sistem yang menjadikan suatu daerah menjadi mandiri. Negara mengharapkan daerah-daerah mampu memanfaatkan otonom masing-masing, supaya tidak tersentralisasi oleh pusat. Selain itu, mampu mengembangkan perekonomian daerah itu sendiri secara penuh tidak terhambat oleh pusat.

Bekasi merupakan salah satunya yang menggunakan sistem otonomi daerah. Dengan banyak jumlah penduduk di Kota Bekasi berdasarkan dari sumber data BPS tahun 2016 adalah sebesar 2.803.283 jiwa, diharapkan mampu memaksimalkan perekonomiannya. Dalam meningkat perekonomian, Kota Bekasi dapat membuat kebijakan fiskal yaitu Pajak Daerah. Pajak Daerah terdiri dari Pajak Bumi dan Bangunan Perdesaan dan Perkotaan, Pajak Reklame, Pajak Penerangan Jalan, Pajak Kendaraan Bermotor, Pajak Bahan Bakar Kendaraan Bermotor dan sebagainya.

Jumlah kendaraan bermotor di Indonesia selalu meningkat setiap tahunnya. Hal ini dapat dirasakan secara langsung, terutama bagi penduduk di kota besar seperti DKI Jakarta dan perbatasannya seperti Bekasi dan lainnya. Dengan begitu kemacetan sering ditemui di seluruh sudut kota dan perbatasan. Hal ini disebabkan karena bertambahnya jumlah kendaraan. Data dibawah ini menunjukkan bahwa kendaraan bermotor di Indonesia selalu bertambah: 
Tabel I.1: Kenaikan Kendaraan Bermotor di Kota Bekasi 2015-2017

\begin{tabular}{|l|r|r|r|}
\hline \multicolumn{1}{|c|}{ Jenis Kendaraan } & \multicolumn{1}{c|}{2015} & \multicolumn{1}{c|}{2016} & \multicolumn{1}{c|}{2017} \\
\hline Mobil Penumpang & 245.586 & 272.620 & 270.439 \\
\hline Bis & 767 & 828 & 755 \\
\hline Mobil Barang & 36.310 & 38.591 & 35.850 \\
\hline Sepeda Motor & 1.164 .900 & 1.256 .639 & 1.128 .755 \\
\hline Jumlah & 1.447 .563 & 1.568 .678 & 1.435 .799 \\
\hline
\end{tabular}

Sumber: Diolah oleh Peneliti dari Samsat Kota Bekasi tahun 2018

Berdasarkan tabel diatas, jumlah kendaraan di kota telah mencapai angka diatas 1,4 juta unit kendaraan. Dengan unit kendaraan terbanyak yaitu sepeda motor. Sepeda motor dalam tabel diatas memiliki rata-rata persentase dalam 3 tahun terakhir sebesar 79,7 \%. Sedangkan untuk unit kendaraan lainnya seperti kendaraan mobil penumpang sebesar $17,7 \%$, Bis sebesar $0,1 \%$ dan mobil barang sebesar 2,5\%. Dengan ini, sepeda motor di Kota Bekasi merupakan potensi besar untuk Pendapatan Asli Daerah.

Meningkatnya jumlah kendaraan bermotor juga diiringi dengan meningkatkan pengkonsumian bahan bakar kendaraan bermotor. Bahan bakar kendaraan bermotor merupakan objek pajak dan salah satu sumber penerimaan dari pajak daerah yang diatur dalam Undang-Undang nomor 28 tahun 2009 tentang Pajak Daerah dan Retribusi Daerah. Pajak Bahan Bakar Kendaraan Bermotor biasa dikenal dengan PBBKB. Penerimaan pajak daerah yang bersumber dari Pajak Bahan Bakar Kendaraan Bermotor tersebut dialokasikan untuk beberapa hal, yaitu salah satunya adalah untuk penanggulangan pencemaran udara dan kerusakan lingkungan. Berdasarkan Peraturan Daerah Provinsi Jawa Barat Nomor 13 Tahun 2011 tentang Pajak Daerah Pasal 78 ayat 1 huruf b menjelaskan bahwa hasil penerimaan PBBKB diserahkan kepada Kabupaten/Kota sebesar 70\% (tujuh puluh persen), berarti untuk Kota Bekasi mendapatkan 70\% alokasi dana penerimaan Pajak Bahan Bakar Kendaraan Bermotor tersebut. Data penerimaan Pajak Bahan Bakar Kendaraan Bermotor di Kota Bekasi sebagai berikut:

Tabel I.2: Target dan Realisasi Pajak Bahan Bakar Kendaraan Bermotor (PBBKB) Kota Bekasi

\begin{tabular}{|c|c|c|c|}
\hline Tahun & Target & Realisasi & $\begin{array}{c}\text { Persentase Pencapaian } \\
\text { Penerimaan PBBKB }\end{array}$ \\
\hline 2015 & $\mathrm{Rp} 186.804 .853 .000$ & $\mathrm{Rp} 202.537 .300 .272$ & $109 \%$ \\
\hline 2016 & $\mathrm{Rp} 186.230 .480 .645$ & $\mathrm{Rp} 174.867 .285 .682$ & $94 \%$ \\
\hline 2017 & $\mathrm{Rp} 182.939 .820 .000$ & $\mathrm{Rp} 187.960 .956 .223$ & $103 \%$ \\
\hline
\end{tabular}

Sumber: Diolah oleh Peneliti dari Bapenda Provinsi Jawa Barat tahun 2018

Berdasarkan tabel I.2, Pajak Bahan Bakar Kendaraan Bermotor di Kota Bekasi pada tahun 2015 dan 2017, realisasi Pajak Bahan Bakar Kendaraan Bermotor telah melampaui target. Namun pada tahun 2016 hanya mencapai $94 \%$.

Tabel I.3: Earmarking Tax Pajak Bahan Bakar Kendaraan Bermotor (PBBKB) di Kota Bekasi

\begin{tabular}{|l|l|c|}
\hline Tahun & Penerimaan Pajak & $\begin{array}{c}\text { Dana Bagi Hasil Pajak dari } \\
\text { Provinsi yang diterima Kota } \\
\text { Bekasi }\end{array}$ \\
\hline 2016 & Rp 202.537.300.272 & Rp 145.579.931.197 \\
\hline 2017 & Rp 174.867.285.682 & Rp 126.832.873.571 \\
\hline 2018 & Rp 187.960.956.223 & Rp 133.174.517.250 \\
\hline
\end{tabular}

Sumber: Diolah oleh Peneliti dari Bapenda Kota Bekasi tahun 2018

Devi Purnama Sari, et.al (Implementasi Kebijakan Earmarking Tax Pajak Bahan Bakar...) 
Berdasarkan tabel diatas, Dana bagi hasil yang diterima oleh Kota Bekasi dari Provinsi Jawa Barat yang berdasarkan Undang-Undang No.28 tahun 2009 dan Peraturan Daerah Jawa Barat No.13 tahun 2011 seharusnya sebesar 70\%, dan berdasarkan tabel diatas pada tahun 2016 Earmarking Tax-nya sebesar 72\% dan juga pada tahun 2017 Earmarking Tax-nya malah meningkat dari tahun sebelumnya menjadi 73\%, namun pada tahun 2018 Earmarking Tax turun menjadi 71\%. Dengan ini dalam 3 tahun terakhir memiliki rata-rata sebesar $72 \%$.

Bahan bakar kendaraan yang telah diproses oleh mesin kendaraan membuat emisi atau gas kendaraan tersebut dapat membuat pencemaran udara dan merusak lingkungan. Berdasarkan sumber berita dari megapolitan kompas 1 juli 2017, menurut Jumhana (2017), “Tingkat polusi di Kota Bekasi sebesar 50 mikrogram dalam Indeks Standar Pencemaran Udara atau dikenal dengan ISPU, disebabkan oleh pabrik dan gas buang kendaraan bermotor." Kurangnya udara bersih di area Kota Bekasi, berdampak kepada warga menderita sakit paru-paru. Kepala Bidang Pelayanan RSUD Kota Bekasi (2017) berkata, "sekitar 100 pasien setiap hari mengantri berobat di Poli Paru tiap harinya."

Tulisan ini mencoba untuk menganalisis tentang penerapan Earmarking Tax Pajak Bahan Bakar Kendaraan Bermotor yang memperoleh alokasi dananya sebesar 70\% dan digunakan untuk penanggulangan pencemaran udara dan kerusakan lingkungan

\section{LITERATUR REVIEW}

Diskusi tentang Earmarking Tax Pajak Bahan Bakar Kendaraan Bermotor. Riant Nugroho Dwijiwijoto (dalam Al fatih, 2010:15) menyatakan "implementasi kebijakan adalah cara agar sebuah kebijakan dapat mencapai tujuannya" sedangkan menurut Al fatih (2010:15) menyatakan implementasi kebijakan adalah penerapan apa yang diamanahkan oleh suatu kebijakan secara baik dan benar dalam rangka mencapai tujuan kebijakan tersebut. Dalam bukunya Public Policy, Riant Nugroho Dwijiwijoto (2014, 494-495) memberi makna implementasi kebijakan sebagai "cara agar sebuah kebijakan dapat mencapai tujuannya. Tidak lebih dan tidak kurang". Ditambahakan pula, bahwa untuk mengimplementasikan kebijakan publik, ada dua pilihan langkah yang ada, yaitu: langsung mengimplementasikan dalam bentuk program atau melalui formulasi kebijakan derivat atau turunan dari kebijakan publik tesebut. Dari beberapa definisi diatas dapat diketahui bahwa implementasi kebijakan menyangkut hal-hal sebagai berikut, yaitu:

1. Adanya tujuan atau sasaran kebijakan

2. Adanya aktivitas atau kegiatan pencapaian tujuan

3. Adanya hasil kegiatan

Pajak Bahan Bakar Kendaraan Bermotor menurut Darwin (2010:113) menjelaskan Pajak Bahan Bakar Kendaraan Bermotor adalah pajak atas bahan bakar yang disediakan atau dianggap digunakan untuk kendaraan bermotor, termasuk bahan bakar yang digunakan untuk kendaraan di air. Oleh sebab itu objek dari Pajak Bahan Bakar Kendaraan Bermotor adalah bahan bakar kendaraan bermotor yang disediakan atau dianggap digunakan untuk kendaraan bermotor, termasuk bahan bakar yang digunakan untuk kendaraan di atas air yaitu: bensin, solar dan gas.

Tax earmarking or what is sometimes called "hypothecation" means differen things to different peope. ... that all revenue from a particular tax is kept saparate from general revenue, can only be used for a specific government expenditure programme and fully founds that programme. (dalam Carling, 2007:1). Sebagai pajak yang penerimaannya telah didesain khusus Earmarking Tax terbagi menjadi dua tipe yaitu full dan partial Earmarking Tax (Michael, 2008:2).

Earmarking Tax adalah kebijakan pemerintah dalam menggunakan anggaran yang sumber penerimaan maupun program pengeluarannya akan secara spesifik ditentukan peruntukannya. (www.fiskal.kemenkeu.go.id).

Earmarking atau earmarked merupakan salah satu pendekatan dalam bidang pengelolaan keuangan publik, khususnya bidang penganggaran atau pengalokasian belanja. Istilah earmarking dalam konteks pengelolaan keuangan publik didefinisikan sebagai suatu kondisi dimana sumber pendapatan negara tertentu dialokasikan kepada kegiatan atau pelayanan publik tertentu. Earmarking sering dikaitkan dalam konteks perpajakan, sehingga kemuadian muncul dan populer earmarked taxes. 
Menurut Rosdiana dan Slemet (2011:92) earmark tax adalah pajak yang dipungut untuk membiayai pengeluaran-pengeluaran tertentu yang sudah spesifik. Sedangkan menurut Ismail (2007:184) earmark adalah kontraprestasi yang sesuai peruntukannya dan harus ditentukan dalam undang-undang maupun peraturan pelaksanannya (Perda), sehingga terdapat kepastian mengenai adanya kewajiban kontraprestasi berupa pelayanan dan besarnya prestase yang dialokasikan pemda untuk pelayanan jenis pajak bersangkutan.

Dalam penerapannya earmarking tax memiliki kelebihan dan kekurangan. Berikut beberapa kelebihan yang dimiliki Earmarking Tax antara lain (Michael, 2008:2-3):

1. Earmarking memiliki jaminan terhadap ketersediaan sumber pendanaan yang dapat diandalkan dan dapat diprediksi. Jaminan terhadap sumberpendanaan memungkinkan dalam hal penyusunan anggaran yang disesuaikan dengan kebutuhan.

2. Earmarking merupakan keputusan pendanaan yang tidak melibatkan faktor politik. Earmarks dicantunkan dalam Undang-undang dan pembiayaannya jelas sehingga menghindari pembiayaanpembiayaan alternatif atau bahkan fiktif dalam sektor politik yang tidak bersangkutan.

3. Earmarking dapat digunakan untuk membangun dukungan politik guna meningkatkan penerimaan atau pendapatan dari sektor pajak.

4. Earmarking membatasi keseluruhan belanja publik dan perpajakan.

Sementara beberapa kekurangan Earmarking Tax adalah (Michael, 2008:3-4):

1. Terjadinya infleksibilitas anggaran. Proses pembuatan anggaran menjadi terlalu rigid dan tidak fleksible. Hal tersebut menyulitkan eksekutif dan legeslatif dalam menentukan anggaran berdasarkan prioritas terhadap program yang paling memberikan kemanfaatan umum.

2. Earmarking dapat digunakan sebagai pembuatan anggaran-anggaran fiktif atau manipulasi terhadap anggaran oleh pihak berkepentingan.

3. Digunakan sebagai subtitusi pendapatan. Earmarking tidak dapat meningkatkan tingkat pembiayaan, sehingga perubahan kebutuhan akan suatu program atau biaya margin yang mungkin muncul sulit direalisasikan melalui earmarking.

4. Earmarking dapat berimplikasi pada kebijakan pajak. Earmarking dapat memunculkan pendukung dan oposisi atas perubahan kebijakan perpajakan terkait reformasi pajak. Hal ini berimbas pada pendapatan pajak yang dialokasikan untuk earmarks.

\section{Implementasi Kebijakan Earmarking Tax Pajak Bahan Bakar Kendaraan Bermotor}

\subsection{Tujuan dan Sasaran Kebijakan Earmarking Tax Pajak Bahan Bakar Kendaraan Bermotor}

Bahan Bakar merupakan kebutuhan masyarakat yang utama pada saat ini sebagai penunjang transportasi. Hal ini dikarenakan setiap masyarakat yang memiliki kendaraan bermotor membutuhkan bahan bakar berupa minyak seperti Premium, Pertamax, dan sebagainya. Tidak hanya masyarakat yang memiliki kendaraan bermotor yang membutuhkan namun juga industry yang mengunakan mesin. Oleh karena itu, menurut Darwin bahan bakar kendaraan adalah Objek pajak dari Pajak Bahan Bakar Kendaraan Bermotor. Sedangkan masyarakat mengunakan bahan bakar tersebut adalah sebagai subjek pajak Pajak Bahan Bakar Kendaraan Bermotor. Akan tetapi masyarakat tidak mengetahui akan hal ini, masyarakat yang membeli bahan bakar dipungut pajak. Pajak tersebut yang dikenal dengan Pajak Bahan Bakar Kendaraan Bermotor atau disingkat PBBKB. Namun dengan masyarakat mengetahui pajak ini, beberapa masyarakat ada yang setuju dan tidak setuju terhadap pungutan pajak tersebut. Beberapa merasa dibebani dan tidak masuk akal. Karena masyarakat mengira setiap membeli sesuatu sudah dikenakan PPN.

Pajak Bahan Bakar Kendaraan Bermotor adalah pajak yang dikenakan atas pembelian atau pengkonsumsian bahan bakar kendaraan bermotor. Menurut Darwin, Pajak Bahan Bakar Kendaraan Bermotor adalah pajak atas bahan bakar yang disediakan atau dianggap digunakan untuk kendaraan bermotor, termasuk bahan bakar yang digunakan untuk kendaraan di air. Pajak Bahan Bakar Kendaraan Bermotor merupakan Pajak Daerah. Menurut Darwin, Pajak Daerah secara umum adalah pajak yang dipungut oleh daerah berdasarkan peraturan pajak yang ditetapkan oleh daerah untuk kepentingan pembiayaan rumah tangganya sebagai badan hukum publik. Dengan ini, Pajak Bahan Bakar Kendaraan 
Bermotor diatur oleh Pemerintah Daerah yaitu Pemerintah Provinsi. Untuk Pajak Bahan Bakar Kendaraan Bermotor wilayah Kota Bekasi sendiri yang mengaturnya adalah Pemerintah Provinsi Jawa Barat dengan Perda Jawa Barat.

Pemungutan Pajak Bahan Bakar Kendaraan Bermotor disebabkan oleh adanya dampak negatif dari penggunaan bahan bakar yaitu berupa emisi kendaraan dan asap pabrik. Menurut Darwin, pemungutan pajak bahan bakar kendaraan bermotor dilakukan oleh produsen dan/atau importer atau nama lain sejenis, atas bahan bakar yang disalurkan atau dijual. Dampak negatif tersebut memiliki pengaruh yang cukup besar yang mengakibatkan kerusakan lingkungan dan kesehatan masyarakat. Contohnya dari memiliki pengaruh ke kesehatan masyarakat seperti masyarakat yang menderita sakit pernafasan atau paru-paru. Dengan ini jika masyarakat sakit akan menimbul biaya lagi untuk daerah karena daerah harus menanggung masyarakat yang sakit. Sedangkan untuk pengaruh ke lingkungan hidup adalah naiknya suhu udara dan udara bersih menipis yang mengakibatkan lapisan udara di langit terkikis oleh emisi kendaraan. Dengan menipisnya lapisan udara tersebut membuat sinar matahari menyengat tubuh. Dengan ini pemerintah sudah membuat suatu kebijakan yaitu Earmarking Tax.

Earmarking Tax merupakan kebijakan alokasi dana dari Pajak Daerah yang telah dipungut dan digunakan sesuai dengan ketentuan yang berlaku. Menurut Rosdiana dan Slemet, earmark tax adalah pajak yang dipungut untuk membiayai pengeluaran-pengeluaran tertentu yang sudah spesifik. Pajak Bahan Bakar Kendaraan Bermotor juga termasuk dalam kebijakan Earmarking Tax. Kebijakan Earmarking Tax Pajak Bahan Bakar Kendaraan Bermotor ini menekan dari tujuan dari adanya pemungutan Pajak Bahan Bakar Kendaraan Bermotor. Jadi tujuan dari dipungutnya Pajak Bahan Bakar Kendaraan Bermotor adalah untuk menanggulangi dampak negatif dan sebagai sumber penerimaan daerah, dengan sasarannya adalah masyarakat Kota Bekasi dengan menfokuskan kepada dampak negatif dari Pajak Bahan Bakar Kendaraan Bermotor. Sedangkan tujuan dari kebijakan Earmarking Tax adalah sebagai alokasi dana untuk dampak yang disebabkan oleh objek pajak terhadap lingkungan dan masyarakat.

\section{2 kegiatan dari Kebijakan Earmarking Tax Pajak Bahan Bakar Kendaraan Bermotor}

Dalam pembahasan ini, kegiatan dari kebijakan ini berawal pada saat pemungutan Pajak Bahan Bakar Kendaraan Bermotor. Sistem pemungutan pajak ini merupakan self-assessment system, dimana wajib pungut memungut pajak yang dikenakan kepada subjek pajak. Pemungutannya secara langsung pada saat subjek pajak membeli objek pajak. Wajib pungut adalah penyalur atau distributor bahan bakar yang menjual produknya ke subjek pajak badan maupun orang pribadi. Berikut adalah proses pemungutan Pajak Bahan Bakar Kendaraan Bermotor.

\section{Gambar III.1 Proses Pemungut PBBKB}

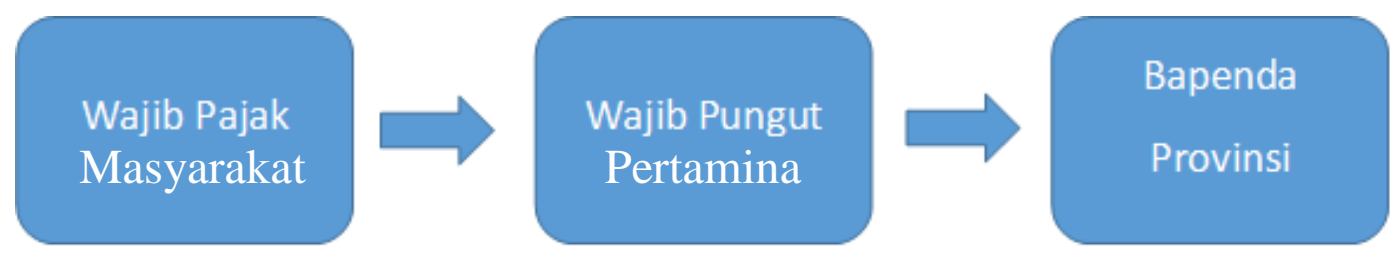

Sumber: diolah oleh peneliti

Dari gambar diatas, dapat terlihat proses pemungutan Pajak Bahan Bakar Kendaraan Bermotor. Wajib pajak membeli bahan bakar dari wajib pungut. Setelah di pungut, wajib pungut diwajibkan untuk laporankan dan menyerahkan jumlah Pajak Bahan Bakar Kendaraan Bermotor yang telah dipungut. Penyerahan melalui transfer ke kode ring atau nomor rekening Bapenda yang telah ditetapkan, untuk pelaporan wajib melakukan rekonsiliasi penerimaan Pajak Bahan Bakar Kendaraan Bermotor kepada pihak Bapenda.

Pajak Bahan Bakar Kendaraan Bermotor memiliki fungsi pajak yaitu sebagai budgetair. Menurut Mardiasmo, fungsi budgetair adalah pajak dipergunakan sebagai alat untuk memasukkan dana secara optimal ke kas negara yang dilakukan sistem pemungutan berdasarkan undang-undang perpajakan yang berlaku. Karena ini merupakan pajak daerah untuk memasukkan dana secara optimal ke kas daerah. Pemerintah Daerah dalam hal penerimaan membuat target pencapaian pajak, target tersebut disebarkan ke daerah-daerah dalam lingkup wilayah. Dikarenakan Pajak Bahan Bakar Kendaraan Bermotor merupakan Pajak Daerah tingkat I maka yang membuat kebijakannya adalah Pemerintah Provinsi, dalam penelitian Kota Bekasi dalam lingkup Provinsi Jawa Barat. 
Tabel III.1 Earmarking Tax

\begin{tabular}{|c|c|c|}
\hline $\begin{array}{c}\text { Dana Bagi Hasil Pajak dari } \\
\text { Provinsi yang diterima Kota } \\
\text { Bekasi }\end{array}$ & $\begin{array}{c}\text { Total Penggunaan } \\
\text { Dana Anggaran }\end{array}$ & $\begin{array}{c}\text { Persentase Penggunaan } \\
\text { Dana Anggaran dari } \\
\text { PBBKB }\end{array}$ \\
\hline $\operatorname{Rp~145.579.931.197}$ & Rp 18.248.333.000 & $13 \%$ \\
\hline $\operatorname{Rp} 126.832 .873 .571$ & Rp 14.750.985.500 & $11 \%$ \\
\hline $\operatorname{Rp} 133.174 .517 .250$ & Rp 14.525.000.000 & $11 \%$ \\
\hline
\end{tabular}

Sumber: diolah oleh peneliti

\section{Diagram III. 1 Earmarking Tax}

\section{Earmarking Tax 2015}

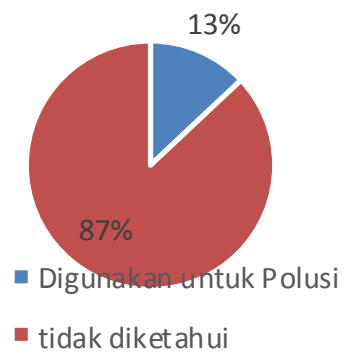

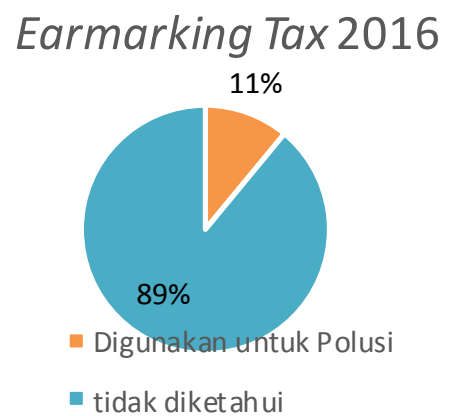

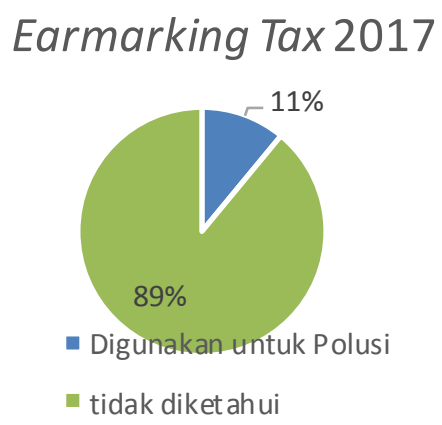

Namun pada pelaksaan kegiatan kebijakan Earmarking Tax Pajak Bahan Bakar Kendaraan Bermotor tidak dilaksanakan sesuai dengan ketentuan dan peraturan yang berlaku, seperti pembagian hasil dari tahun 2016 sampai dengan 2018, berdasarkan Undang-Undang no. 28 tahun 2009 dan Perda Jawa Barat no. 13 tahun 2011 tertulis untuk penerimaan dari Pajak Bahan Bakar Kendaraan Bermotor 70\% diserahkan kepada Kabupaten/Kota. Realisasi Earmarking Tax untuk tahun 2016 sebesar Rp 145.579.931.197 dari penerimaan Pajak Bahan Bakar Kendaraan Bermotornya sebesar Rp 202.537.300.272, untuk dalam persentase adalah 72\% dari penerimaan pajaknya. Hal ini sama untuk tahun 2017 dan 2018, untuk Earmarking Tax untuk tahun 2017 sebesar Rp 126.832.873.571 dari penerimaan Pajak Bahan Bakar Kendaraan Bermotornya sebesar Rp 174.867.285.682, untuk dalam persentase adalah 73\% dari penerimaan pajaknya. Sedangkan untuk Earmarking Tax untuk tahun 2018 sebesar Rp 133.174.517.250 dari penerimaan Pajak Bahan Bakar Kendaraan Bermotornya sebesar Rp 187.960.956.223, untuk dalam persentase adalah $71 \%$ dari penerimaan pajaknya.

Setelah diterimanya Earmarking Tax dari Bapenda Provinsi, Pemerintah Kota Bekasi melakukan penganggaran untuk melaksanakan program-program pemerintahannya. Berikut adalah alur Penganggaran atau penyusunan APBD.

\section{Gambar III.2 Alur Penganggaran APBD}

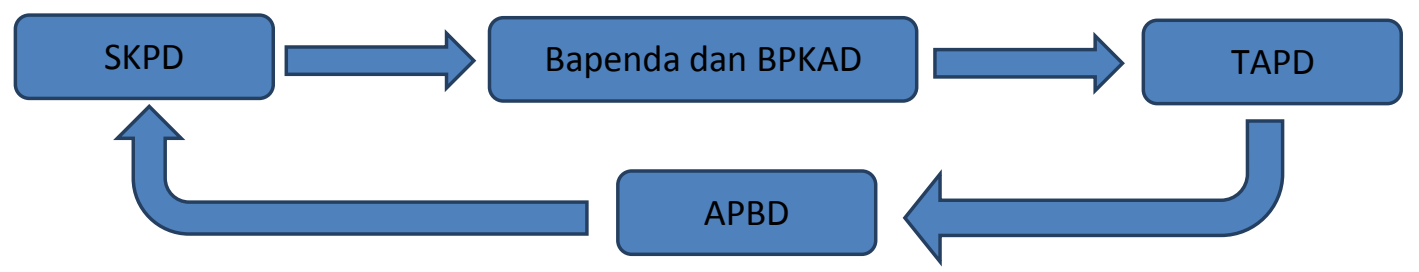

Sumber: Data Primer, yang diolah oleh peneliti

Berdasarkan gambar diatas dijelaskan sebagai berikut, bahwa proses pertama setiap SKPD akan menyusun rencana kerja dan anggaran (RKA) dengan batas waktu sampe bulan Mei dan mengajukan Kepada penyusun anggaran yang diwakili oleh BPKAD dan BAPENDA, batas waktu pengajuan adalah bulan November. Proses kedua penyusunan rancangan anggaran oleh setiap SKPD ini disesuaikan dengan prioritas anggaran. Proses ketiga yang dilakukan adalah RKA dari semua SKPD akan dikaji dan dievaluasi oleh 
TAPD yang terdiri dari Bappeda, Bapenda, BPKAD, Setda. Setelah itu dana akan dimasukan APBD dengan persetujuan Walikota dan DPRD. Kemudian SKPD akan mendapat alokasi dana yang telah ditetapkan.

Untuk pengalokasian Pajak Bahan Bakar Kendaraan Bermotor, digunakan untuk penanggulangi polusi udara, yakni SKPD yang menangani hal tersebut adalah Dinas Lingkungan Hidup. Menurut informasi yang peneliti terima informan bahwa pengalokasian dana untuk penanggulangi polusi udara sebesar $10 \%$ dari Earmarking Tax. Namun dalam pelaksanaannya dalam diagram IV.3, pengalokasian dana selama 3 tahun terakhir dengan rata-rata sebesar $12 \%$ dari Earmarking Tax. Kegiatan yang dilakukan dalam penganggaran adalah Program Pengelolaan Ruang Terbuka Hijau (RTH), Program Pengendalian Pencemaran dan Kerusakan Lingkungan Hidup dan Program Peningkatan Pengendalian Polusi.

\subsection{Hasil dari Kegiatan Kebijakan Earmarking Tax Pajak Bahan Bakar Kendaraan Bermotor}

Berdasarkan kegiatan dalam penganggaran yang telah dilaksanakan oleh Dinas Lingkungan Hidup, menurut hasil penelitian yang peneliti lakukan menghasilkan tingkat polusi udara untuk wilayah pusat kota masih dalam status normal dalam Indeks Standar Polusi Udara. Namun untuk beberapa daerah diwilayah Kota Bekasi tingkat polusinya masih cukup tinggi. Dikarenakan pelaksanaan kegiatan belum merata dan pemanfaatan dana alokasi belum maksimal.

\section{CONCLUSIONS}

Implementasi Kebijakan Earmarking Tax Pajak Bahan Bakar Kendaraan Bermotor di Kota Bekasi masih belum berhasil disebabkan oleh kegiatan dari kebijakan tidak sesuai dengan ketentuan yang berlaku dan belum maksimal. Walaupun dari dalam tujuan dan sasaran kebijakan telah dijalankan dengan sesuai dan hasil dari kegiatan yang belum maksimal tetapi telah dirasakan hasilnya. Oleh karena itu walaupun dari 3 indikator untuk mengukur keberhasilan implementasi kebijakan, kebijakan ini sudah memenuhi 2 indikator maka kebijakan dapat dikatakan belum berhasil dalam implementasinya.

\section{REFERENCES}

Al Fatih, Andy. 2010. Implementasi Kebijakan dan Pemberdayaan Masyarakat. Bandung: UNPAD Press

Carling, Robert. 2007. “Tax Earmarking is It Good Practice?". The Center for Independent Studies, Perspectives on Tax Reform (12).

Darwin. 2010. Pajak Daerah dan Retribusi Daerah. Jakarta: Mitra Wacana Media

Dwidjowijoto, Riant Nugroho. 2014. Public Policy. Jakarta: Elex Media Komputindo.

Ismail, Tjip. 2007. Pengaturan Pajak Daerah di Indonesia. Jakarta: Yellow Printing.

Michael, Joel. (2008, January). Earmarking State Tax Revenues. Minnesota House of Representatives Research Departmen. Legeslatitive Analisys, 1-6.

Rosdiana, Haula dan Edi Slamet Irianto. 2011. Pengantar Ilmu Pajak: Kebijakan dan Implementasi di Indonesia. Jakarta: Rajawali Pers. 